\title{
Evidence Based Review of Natural Health Products for Non-Specific Low Back Pain
}

\author{
Joel J. Gagnier*
}

Department of Epidemiology, School of Public Health, University of Michigan, Ann Arbor, Michigan, USA

\begin{abstract}
Introduction - Natural health products (e.g., vitamins, minerals, herbal medicines) are frequently used for musculoskeletal pain and there is an increasing amount of high quality research being done to test the efficacy of these interventions. Low back pain is a very common condition and individuals suffering from these conditions are frequently seeking out these products.
\end{abstract}

Objective - The objective of this paper is to review and summarize the evidence surrounding natural health products for chronic non-specific low back pain.

Methods - We searched for systematic reviews and randomized controlled trials in PubMed and the Cochrane Library. We performed a best evidence synthesis of the resulting papers.

Results - We included two systematic reviews and 2 additional randomized controlled trials published subsequently to these reviews. We found strong evidence for $50 \mathrm{mg}$ harpagoside per dose of an aqueous extract of Harpagophytum procumbens per day reduces pain more than placebo. We found moderate evidence for $100 \mathrm{mg}$ harpagoside per dose of an aqueous extract of Harpagophytum procumbens compared to placebo, for an extract of willow bark yielding $120 \mathrm{mg}$ salicin per day compared with placebo, for $240 \mathrm{mg}$ of salicin per day in reducing pain to a greater extent than placebo, for $240 \mathrm{mg}$ of salicin per day as equivalent to $120 \mathrm{mg}$ salicin, for no differences in pain and function between a $60 \mathrm{mg}$ daily harpagoside dose of an aqueous extract of Harpagophytum procumbens and $12.5 \mathrm{mg}$ rofecoxib per day, for no difference in pain and overall improvement between Spiroflor SRL homeopathic gel (SRL) and Cremor Capsici Compositus FNA, the capsici oleoresin gel, for intramuscular B12 when compared with placebo. We found limited evidence for topical Capsicum frutescens in the form of Rado-Salil cream or a Capsicum plaster for reducing pain more than placebo, for lavender oil in the treatment of chronic NSLBP, or vitamin C, zinc, and manganese in addition to prolotherapy. Adverse events for all interventions appeared to be mild and transient though we did not attempt to identify all relevant literature concerning adverse events.

Conclusions - There is some evidence for several natural health products in the treatment of chronic non-specific low back pain. More research is needed for all of these interventions before they are incorporated into routine clinical practice and their reporting must be improved by referring to the recently published extensions of the CONSORT statement.

Keywords: Herbal medicine, natural health products, vitamins, minerals, low-back pain.

\section{INTRODUCTION}

Complementary and alternative medicine (CAM) interventions include nutritional or dietary supplements (i.e. vitamins, minerals, etc.) acupuncture, chiropractic medicine, massage therapy etc. Nutritional supplements, also called dietary supplements or natural health products, are a vast and heterogeneous group of substances that includes: herbal interventions vitamins, minerals, accessory nutrients (e.g. Coenzyme Q10), macronutrients (e.g. fatty acids, amino acids) and other substances such as glucosamine, bee pollen etc [1-3].

*Address correspondence to this author at the Department of Epidemiology, School of Public Health, University of Michigan, 1415 Washington Heights, Rm M5158, Ann Arbor, MI, 48109-2029, USA;

E-mail: jgagnier@umich.edu
The use of natural health products has become prevalent in westernized societies $[4,5]$. A recent survey in Canada found that $37 \%$ of the individuals who reported back pain visited a CAM practitioner compared with only $17 \%$ of the entire population [6]. On survey found that back pain patients were willing to try CAM therapies and to learn about each of these therapies [7]. The amount of research being performed and published exploring complementary and alternative medicine (CAM) interventions is growing steadily. The number of randomized trials of CAM has been doubling approximately every five years [8]. In addition, CAM-teaching institutions are now beginning to teach principles of evidence-based medicine and mainstream medical schools are teaching CAM interventions [9, 10]. These initiatives are timely given the large number of visits to CAM practitioners in North America [4]. The objective of the present paper was to determine the effectiveness of nutritional interventions and herbal medicine interventions 
compared to placebo, no intervention, or other interventions for chronic non-specific low-back pain (NSLBP).

\section{METHODS OF REVIEW}

We included only systematic reviews and randomized controlled trials (RCT) testing nutritional supplements or herbal medicine interventions for chronic (12 or more weeks) non-specific low back pain. We searched PubMed and the Cochrane library up to for relevant papers (see appendix 1 for search terms). We also reviewed citation lists from retrieved articles and consulted experts in the area. We did not assess the methodological or reporting quality of these reviews or trials, but chose only to discuss their findings. We decided to perform a best evidence synthesis by rating the overall level of evidence of these interventions using the rating system developed by van Tulder (2003; see Table 1) [11].

\section{RESULTS OF LITERATURE SEARCH}

Our search for systematic reviews in both databases resulted in identifying 28 systematic reviews. After reviewing the abstracts and full texts of the reviews 26 were excluded, resulting in the inclusion of 2 systematic reviews $[12,13]$; see Fig. (1). Reviews were excluded for a variety of reasons. For example, one review included participants with NSLBP, with a trial using mineral water as a co-intervention, but whose population had sub-acute NSLBP (4-12 weeks), and therefore it was excluded [14]. An additional review [15] examining acupuncture for low back pain included several trials using herbal medicines but only for acute low back pain, thus it was excluded. Another review reported on the use of traditional Chinese herbal medicines and reported outcomes for low back pain in several of the included trials but it was not possible to determine if this was truly NSLBP, therefore this review was excluded [16]. Two additional reviews reported appropriate search methods but did not describe any additional systematic review methods and thus were excluded $[17,18]$. One of the included reviews reported on herbal medicines for NSLBP and one review for vitamin and mineral interventions. Both of the reviews were published in the Cochrane library and had strong methods and were well reported. These reviews included several randomized controlled trials including a herbal medicine [1927]. Our search for randomized controlled trials resulted in the identification of 149 titles and upon reviewing abstracts and full texts 145 were excluded for various reasons including: not being an RCT, not including a population suffering from chronic NSLBP, not testing an herbal medicine or nutritional supplement, or being included in one of the reviews above. This resulted in a total of 2 randomized controlled trials [28-30]; see Fig. (2). Table $\mathbf{2}$ and $\mathbf{3}$ describe the included reviews and randomized controlled trials.

We extracted data on adverse events from isolated systematic reviews and RCTs. We also searched for adverse events and drug interaction information using PubMed and EMBASE. Data was extracted from each review and RCT by one individual.

\section{HERBAL MEDICINES FOR CHRONIC NSLBP}

\section{History and Mechanisms of Actions of Herbal Medicines}

We determined that 4 herbal species have some evidence for use in chronic NSLBP.

\section{Harpagophyum Procumbens}

(Devil's claw) has been used for many years in the Kalahari Desert to treat complications arising in pregnancy, for skin disorders, for various gastrointestinal disturbances, and for rheumatic and general musculoskeletal pains [31]. There have been a host of preclinical studies looking at the mechanism of action of Devil's Claw. Generally, the various mechanisms of action that are likely related to its effects on low back pain include: anti-inflammatory effects through the suppression of leukotriene formation, inhibition of cyclooxygenase enzymes and platelets and an analgesic effect due to reduction in expression of $\mathrm{PGE}_{2}$ [31].

Willow bark is a plant that has been used for many hundreds of years in many parts of the world for varying complaints including general pain and for its antipyretic effects. There are several species of willow bark including Salix alba, Salix purpurea and Salix daphnoides. It appears that willow bark and its compounds inhibit cyclooxygenase2, lipoxygenase, cytokine release, and hyaluronidase [32].

Capsicum frutescens is a plant that has been used in foods and as a tradtional medicine for many centuries. In particular, it has been used traditionally for various gastrointestinal complaints and topically for many types of pain. The mechanism of action of Capsicum appears to include the stimulation of afferent $\mathrm{C}$ fibers, followed by a refractory period with reduced sensitivity and with repeated applications, persistent desensitization, resulting in the depletion of substance P [33].

Finally, lavender appears to possess some antiinflammatory and analgesic effects but further research is required to delineate the mechanisms of action [34].

Table 1. Levels of Evidence

\begin{tabular}{|c|c|}
\hline Level of Evidence & Description/Operational Definition \\
\hline \hline Strong evidence & consistent findings among multiple high quality RCTs \\
\hline Moderate evidence & consistent findings among multiple low quality RCTs and/or one high quality RCT \\
\hline Limited evidence & one low quality RCT \\
\hline Conflicting evidence & inconsistent findings among multiple RCTs \\
\hline No evidence & no RCTs \\
\hline
\end{tabular}




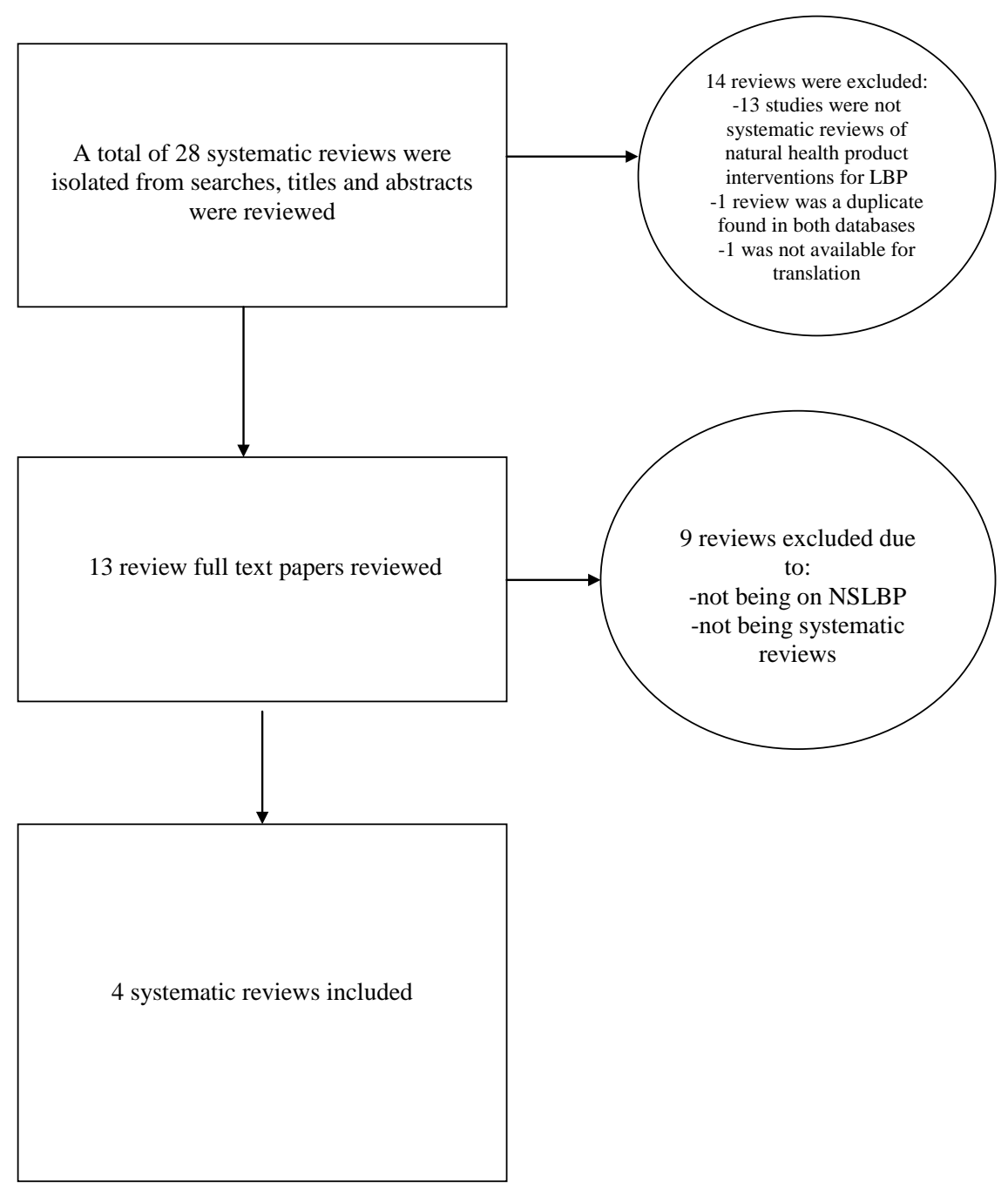

Fig. (1). Search results for systematic reviews.

\section{Evidence from the Literature}

\section{Harpagophytum Procumbens (Devil's Claw) Versus Placebo [12]}

One review included two RCTs [19, 20], both of which included participants suffering from acute exacerbations of chronic NSLBP of greater than 6 months. One review [12] found that there is strong evidence from two high quality RCTs $(n=325)$ that $50 \mathrm{mg}$ harpagoside (the purported active constituent of Harpagophytum procumbens) per dose of an aqueous extract of Harpagophytum procumbens per day reduces pain more than placebo in the short-term $[19,20]$. In addition, this review reports that there is moderate evidence that $100 \mathrm{mg}$ harpagoside per dose of an acqueous extract of Harpagophytum procumbens reduces pain more than placebo for at least 5 days in the fourth week of treatment [20].

\section{Salix Daphnoides and Salix Purpurea Versus Placebo [12]}

One review included two RCTs, both of which included participants suffering from acute exacerbations of chronic NSLBP [21, 22]. One trial did not report clinically relevant outcomes [22]. The review found that there is moderate evidence from one high quality trial $(n=210)$ that an extract of willow bark, containing Salix daphnoides and Salix purpurea, yielding $120 \mathrm{mg}$ salicin per day leads to more pain free patients in the short-term, and that a dose yielding 240 $\mathrm{mg}$ of salicin per day reduces pain to a greater extent than placebo or a daily dose equivalent to $120 \mathrm{mg}$ salicin [21].

\section{Capsicum Frutescens Versus Placebo [12]}

One review reports on one small RCT including patients with acute NSLBP [23], though the actual duration of LBP in this study was not described. This review also described another RCT ( $\mathrm{N}=154)$ which found that a plaster of Capsicum frutescens with $11 \mathrm{mg}$ capsaicinoids reduces pain and improves function more than placebo for the treatment of acute episodes of chronic non-specific LBP in the shortterm [24]. Therefore there is limited evidence for Rado-Salil cream or a Capsicum plaster for reducing pain more than placebo in the treatment of acute non-specific LBP in the short-term.

\section{Harpagophytum Procumbens Versus Rofecoxib [12]}

One review included a single RCT including 88 participants and found that there is moderate evidence that there are no differences in pain and function between a 60 mg daily harpagoside dose of an aqueous extract of Harpagophytum procumbens and $12.5 \mathrm{mg}$ rofecoxib per day in the treatment of acute episodes of chronic NSLBP in the short-term [25]. 


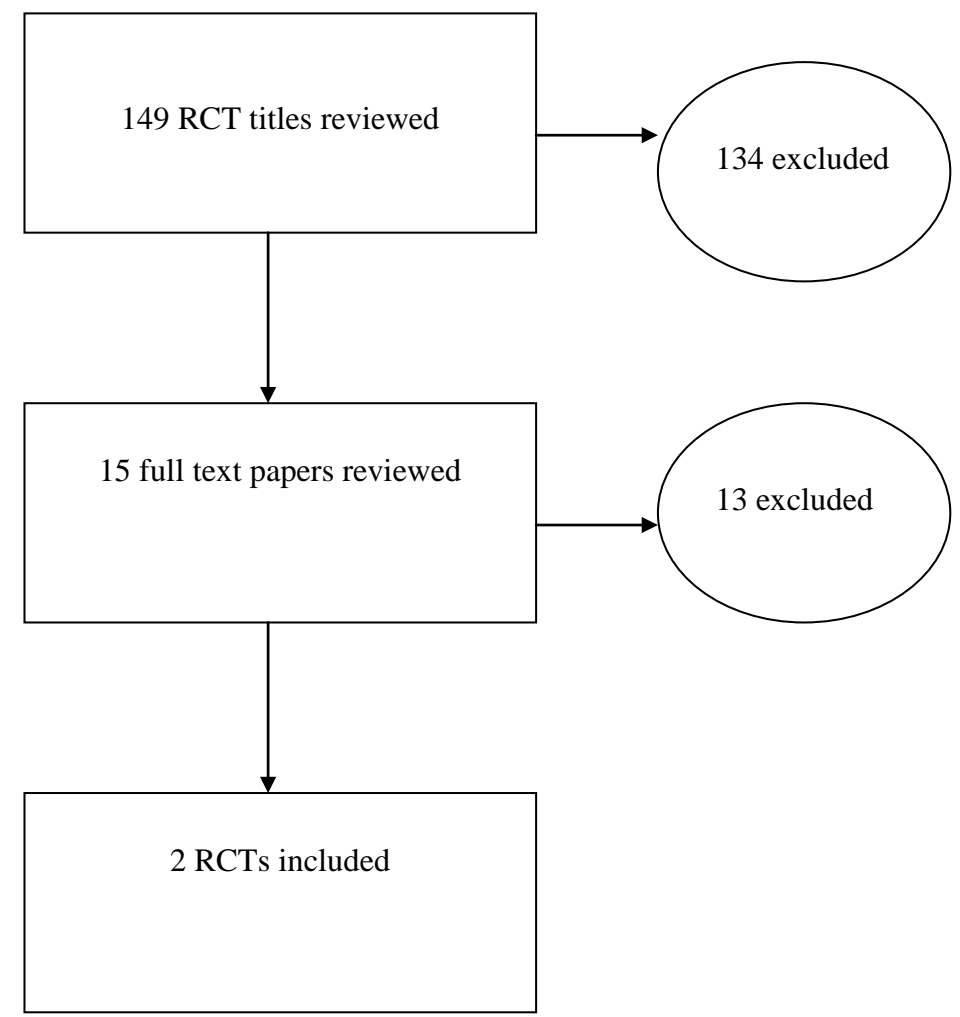

Fig. (2). Search results for randomized controlled trials.

\section{Salix Alba Versus Rofecoxib [12]}

One review included a single RCT $(\mathrm{n}=228)$ and concluded that there is moderate evidence that there are no differences in pain and function between a $240 \mathrm{mg}$ salicin dose of an extract of Salix alba and $12.5 \mathrm{mg}$ rofecoxib per day in treatment of acute episodes of chronic NSLBP in the short-term [26].

\section{Capsicum Frutescens Versus Homeopathic Treatment [6]}

One review included a single RCT testing a capsicum gel against a homeopathic gel. This review found that there is moderate evidence that there are no differences in pain and overall improvement between Spiroflor SRL homeopathic gel (SRL) and Cremor Capsici Compositus FNA, the capsici oleoresin gel [27]. This trial did not include a placebo control and the efficacy of the homeopathic gel is unknown, thus the absolute efficacy of each intervention is difficult to determine. Therefore, there is limited evidence for the efficacy of a Capsicum frutescens gel in the treatment of chronic NSLBP.

\section{Lavender Oil in Addition to Acupoint Stimulation and Acupressure Versus Usual Care [28]}

One RCT included 61 participants (32 active group, 29 usual care group) with sub-acute or chronic NSLBP. The active group received acupoint stimulation followed by acupressure with lavender oil for eight sessions over a period of 3 weeks. One week after the end of treatment the active group had a 39\% greater reduction in the visual analogue scale for pain intensity than the usual care group $(\mathrm{p}<0.001)$ as well as improved walking time and greater later spine flexion. It is impossible to delineate the variable effects of each intervention in this trial, thus there is limited evidence for lavender oil in the treatment of chronic NSLBP.

\section{VITAMINS AND MINERALS FOR CHRONIC NSLBP}

\section{History and Mechanisms of Vitamins and Minerals}

Early theories on the cause of beriberi pointed to the formation of toxins by improper cooking, preservation, or storage; however, feeding experiments with standardized food pointed at the existence of 'accessory factors', present in food in small amounts. These factors seemed to be essential for metabolic processes but could not be synthesized by an organism.

In 1912 Cashmir Funk named these growth factors "vitamines" because they were required for life ("vita") and because he found that thiamine isolated from rice husks contained nitrogen ("amine"). Funk's original term "vitamine" was changed to "vitamin" when many scientists identified, purified, and synthesized all of the vitamins and discovered they did not all contain nitrogen. The period from 1912 to 1948 saw the isolation and identification of individual factors belonging to a variety of chemical classes collectively labeled as 'vitamins' [35].

The history of the understanding of the importance of minerals to animal structure and function can be traced to experiments in which determined the mineral content of tissues and fluids [36]. Following from this, research began exploring the specific functions of these minerals and began testing their utility in the prevention and treatment of various conditions. Vitamin C, zinc and manganese were used in one study [29] and were purported to be used to promote collagen growth and to support optimal strengthening of the treated ligaments. Vitamin B12, used in another study [30], is reported to have anti-nociceptive and anti-inflammatory properties. 
Table 2. Description of Included Systematic Reviews.

\begin{tabular}{|c|c|c|c|c|c|c|}
\hline Reference & Design & $\begin{array}{c}\text { Particip Ants; Inclusion/Exclusion } \\
\text { Criteria }\end{array}$ & Intervention & Outcomes & Results & Comments \\
\hline$[12]$ & $\begin{array}{c}\text { Systematic } \\
\text { review }\end{array}$ & $\begin{array}{l}10 \text { RCTs, including adults (18 } \\
\text { years and older) suffering } \\
\text { from acute (up to } 6 \mathrm{wk} \text { ), } \\
\text { sub-acute (6-12 wk), or } \\
\text { chronic (more than } 12 \mathrm{wk} \text { ) } \\
\text { nonspecific low back pain. }\end{array}$ & $\begin{array}{l}\text { Herbal medicines: } \\
\text { defined as a plant } \\
\text { that is used for } \\
\text { medicinal } \\
\text { purposes in any } \\
\text { form. }\end{array}$ & $\begin{array}{c}\text { Primary } \\
\text { outcome } \\
\text { measures } \\
\text { were pain and } \\
\text { function }\end{array}$ & $\begin{array}{l}\text { H procumbens, } S \\
\text { alba, and } \mathrm{C} \\
\text { frutescens seem to } \\
\text { reduce pain more } \\
\text { than placebo. } \\
\text { Additional trials } \\
\text { testing herbal } \\
\text { medicines against } \\
\text { standard treatments } \\
\text { are needed. }\end{array}$ & $\begin{array}{l}\text { The quality of } \\
\text { reporting in these } \\
\text { trials was generally } \\
\text { poor; thus, trialists } \\
\text { should refer to the } \\
\text { CONSORT } \\
\text { statement for herbal } \\
\text { interventions }\end{array}$ \\
\hline [13] & $\begin{array}{c}\text { Systematic } \\
\text { review }\end{array}$ & $\begin{array}{c}\text { Four RCTs, including } \\
\text { participants over the age of } \\
16 \text { years, suffering from } \\
\text { chronic (defined as greater } \\
\text { than } 12 \text { wk) nonspecific low } \\
\text { back pain. }\end{array}$ & $\begin{array}{c}\text { Prolotherapy } \\
\text { solutions injected } \\
\text { into the ligaments } \\
\text { and tendons that } \\
\text { are the source } \\
\text { of pain. One RCT } \\
\text { added oral } \\
\text { vitamin C, zinc, } \\
\text { and manganese } \\
\text { supplements } \\
\text { daily. }\end{array}$ & $\begin{array}{c}\text { Pain, low } \\
\text { back-related } \\
\text { disability, } \\
\text { overall } \\
\text { improvement } \\
\text { or satisfaction } \\
\text { with treatment, } \\
\text { well-being, } \\
\text { other disability, } \\
\text { physical } \\
\text { examination }\end{array}$ & $\begin{array}{l}\text { In the single RCT } \\
\text { that added } \\
\text { vitamins and } \\
\text { minerals to both } \\
\text { groups (active and } \\
\text { control), there was } \\
\text { improvement from } \\
\text { baseline for each of } \\
\text { the measurement } \\
\text { points up to } 24 \text { mo. } \\
\text { There were no } \\
\text { differences between } \\
\text { the groups. }\end{array}$ & $\begin{array}{l}\text { Future research is } \\
\text { needed to test the } \\
\quad \text { effects of } \\
\text { prolotherapy with } \\
\text { and without added } \\
\text { vitamins and } \\
\text { minerals. }\end{array}$ \\
\hline
\end{tabular}

\section{Evidence from the Literature}

\section{Vitamins and Minerals Plus Prolotherapy ${ }^{1}$ [13]}

One review found one RCT that included 110 participants with chronic NSLBP with or without radiation into the legs [29]. The experimental group $(n=54)$ received fortnightly injections of lumbo-pelvic ligaments with glucose $(20 \%)$ and lignocaine $(0.2 \%), 10$ to $30 \mathrm{ml}$ and the control group (C) $(\mathrm{n}=56)$ fortnightly injections of lumbo-pelvic ligaments with saline $(0.9 \%), 10$ to $30 \mathrm{ml}$. In addition both groups received superficial injections of lignocaine over deep injection points; oral vitamin $\mathrm{C}$, zinc and manganese supplements daily. Both groups improved from baseline for each of the measurement points up to 24 months. It is difficult to determine the relative effects of the vitamins and minerals on the improvement of NSLBP in these participants. Thus there is limited evidence of the effectiveness of vitamin C, Zinc and manganese in addition to prolotherapy for NSLBP. Future research is needed to test the effects of prolotherapy with and without added vitamins and minerals.

\section{Intramuscular Vitamin B12 Versus Placebo [30]:}

A single RCT tested the efficacy and safety of intramuscular vitamin B12 (IM B12; Tricortin 1000) in the treatment of low back pain in 60 participants with chronic NSLBP or sciatic neuritis of mechanical origin without need

${ }^{1}$ Prolotherapy is the injection of a non-pharmacological and non-active irritant solution into tissue (e.g., tendons or ligaments) to stimulate the production of connective tissue with the aim of strengthening that tissue. for surgical procedures and with no signs of B12 deficiency. Injections of placebo or B12 were given once per day for a period of two weeks. Both groups experienced a sharp decrease in pain with the active treatment (IM B12) with the active (B12) group having a greater decrease $(\mathrm{p}<0.0001)$. In the B12 group the visual analogue score changed from 75.54 to $9.53(\mathrm{p}<0.0001)$ and in the placebo group from 70.63 to 36.83 ( $\mathrm{p}<0.0001)$. Also, the disability index was decreased in both groups and to a greater degree in the active group $(p<0.0002)$. Finally, the mean consumption of paracetamol rescue medication was lower in the active group $(\mathrm{p}<0.0001)$. In addition, consumption of paracetamol proved significantly higher in the placebo group than in the active treatment. There is moderate evidence that IM B12 is effective for chronic NSLBP.

\section{DISCUSSION}

There are many nutritional supplements used by a large percentage of the population. In some cases these interventions, especially herbal medicine, are used traditionally and have been for many centuries. These interventions available on the market in many countries worldwide often on an over the counter basis, and are not being prescribed or suggested by qualified health care practitioners. Individuals suffering from NSLBP seek out nutritional supplements, herbal medicines and visit CAM practitioners who may suggest these interventions. Healthcare practitioners giving advice on such products should be qualified and well-trained and have access to the highest 
Table 3. Description of Included Randomized Controlled Trials

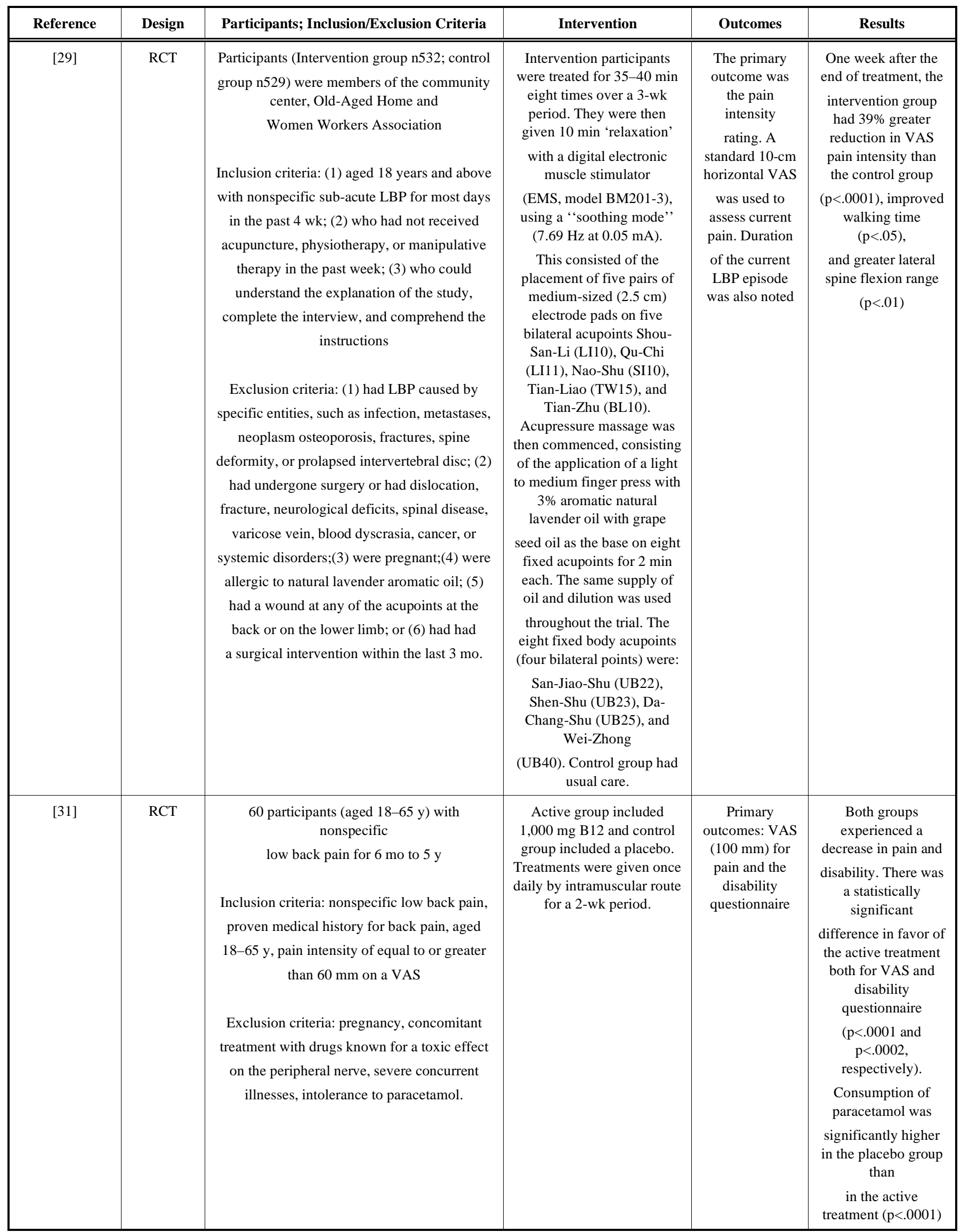


Table 4. Summary of Evidence for Natural Health Products

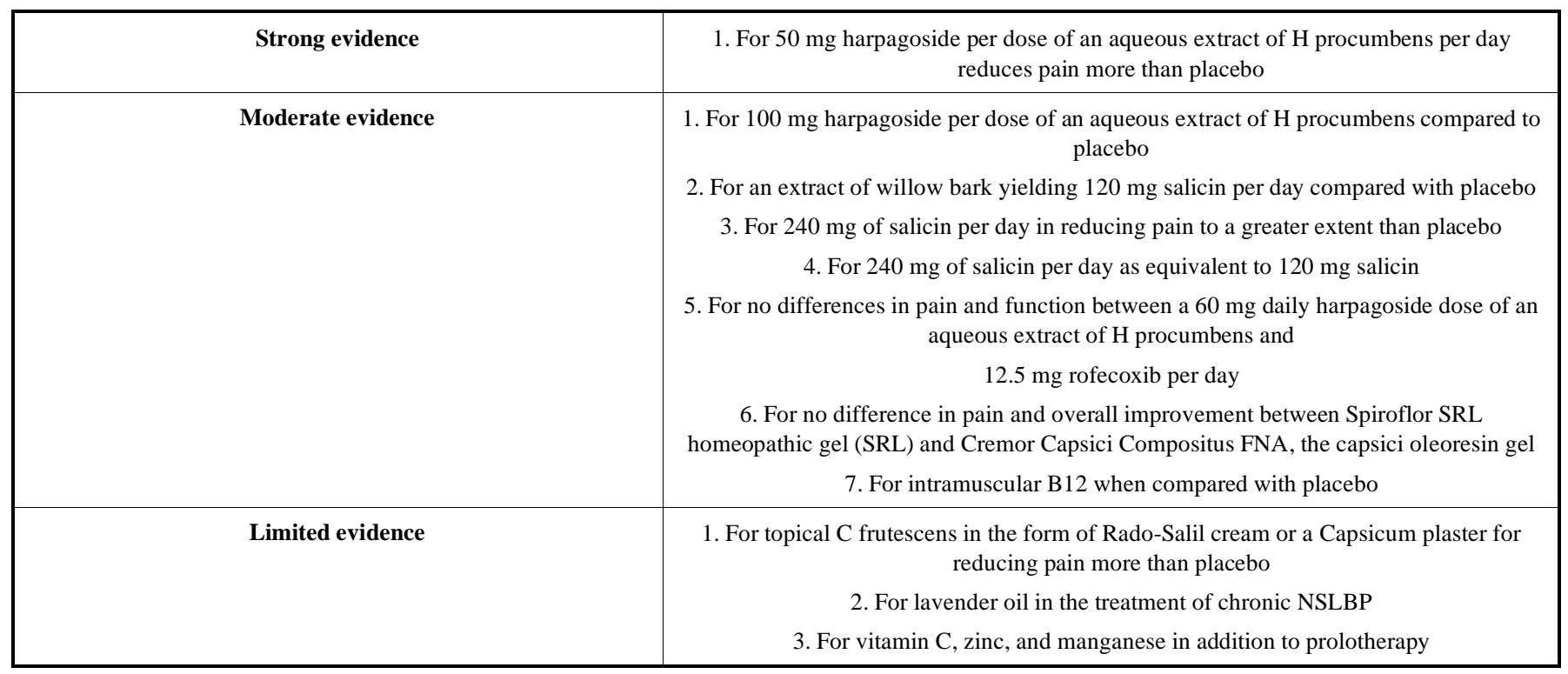

quality scientific evidence. Table 4 contains a summary of evidence for these interventions.

We found that there is some evidence for various herbal medicines, vitamins and minerals for chronic non-specific low back pain in adults. We found strong evidence for $50 \mathrm{mg}$ harpagoside per dose of an aqueous extract of $\mathrm{H}$ procumbens per day reduces pain more than placebo. We found moderate evidence for $100 \mathrm{mg}$ harpagoside per dose of an aqueous extract of $\mathrm{H}$ procumbens compared to placebo, for an extract of willow bark yielding $120 \mathrm{mg}$ salicin per day compared with placebo, for $240 \mathrm{mg}$ of salicin per day in reducing pain to a greater extent than placebo, for $240 \mathrm{mg}$ of salicin per day as equivalent to $120 \mathrm{mg}$ salicin, for no differences in pain and function between a $60 \mathrm{mg}$ daily harpagoside dose of an aqueous extract of $\mathrm{H}$ procumbens and $12.5 \mathrm{mg}$ rofecoxib per day, for no difference in pain and overall improvement between Spiroflor SRL homeopathic gel (SRL) and Cremor Capsici Compositus FNA, the capsici oleoresin gel, for intramuscular B12 when compared with placebo. We found limited evidence for topical $\mathrm{C}$ frutescens in the form of Rado-Salil cream or a Capsicum plaster for reducing pain more than placebo, for lavender oil in the treatment of chronic NSLBP, or vitamin C, zinc, and manganese in addition to prolotherapy.

In addition, though we did not review the complete evidence for harm if these interventions it appears that the clinical trials and reviews included suggest minimal side effects, limited mostly to mild gastrointestinal upset. A note of caution, capsicum creams can be very irritating to certain skin types including those with fair skin or those known to have reactions to topical irritants, and capsicum can be irritating to mucous membranes.

We do not address herb/nutrient-drug interactions here. The mechanisms of several of these substances might interfere with several medications. For example, we would suggest that patients taking vitamin $\mathrm{k}$ antagonists not use willow bark products due to their platelet inhibiting effects. In general it appears these interventions are safe, but one should perform a careful review of any medications being considered to be taken concurrently to ensure safety.

This review has several drawbacks. First, only a single individual performed searches, screened and included trials, extracted data and assessed evidence. It is possible that decisions pertaining to each of these methodological components may have been slightly altered had there been a second reviewer and following directly from this, the results and conclusions of this paper may have been different. Also, this review did not perform a meta-analysis of the data. Meta-analytical methods were not possible due to the underreporting of specific data in these trials and the heterogeneity of the populations and interventions. Finally, most of the randomized trials included in the systematic reviews and the additional RCTs included in this review were poorly reported. That is, often it was difficult to gain a complete understanding of the intervention characteristics. We advise that all clinical investigators refer to the extensions of the CONSORT statement for relevance to herbal medicines [37-39] and non-pharmacological therapies [40] when reporting clinical trials on these products. It is imperative that all the relevant information for these trials be reported to allow readers to adequately assess the internal and external validity of these trials.

On the other hand, this review has several strengths including the use of comprehensive search strategies across multiple databases, the assessment of trials for inclusion, extraction of data and assessment of overall evidence.

We hope that this review is useful for clinicians in choosing NHPs for the treatment of NSLBP. Also, we hope that researchers will perform the suggested research such that the scientific evidence is expanded upon so that we may gain a more complete understanding of the efficacy and safety of NHPs for chronic NSLBP.

\section{REFERENCES}

[1] What is complementary and alternative medicine? Available from: [http://nccam.nih.gov/health/whatiscam/] 
[2] Dietary Supplement Health and Education Act of 1994 [http://www.cfsan.fda.gov/ dms/dietsupp.html]

[3] Her Majesty the Queen Natural Health Products Regulations. Canada Gazette Part II 2003; vol. 137(13): pp. 1562-1607.

[4] Eisenberg DM, Davis RB, Ettner SL, et al. Trends in alternative medicine use in the united states, 1990-1997. JAMA 1998; 280: 1569-75.

[5] Baseline Natural Health Products Survey Among Consumers [http://www.hcsc.gc.ca/dhp-mps/pubs/natur/eng_cons_survey_e.html]

[6] Millar WJ. Patterns of use: Alternative health-care practitioners. Health Rep 2001; 13: 9-22.

[7] Sherman KJ, Cherkin DC, Connelly MT, et al. Complementary and alternative medical therapies for chronic low back pain: what treatments are patients willing to try? BMC Complement Altern Med 2004; 4: 9.

[8] Vickers A. Recent advances: complementary medicine. BMJ 2000; 321: 683-6.

[9] Mills EJ, Hollyer T, Guyatt G, Ross CP, Saranchuk R, Wilson K. Teaching evidence-based complementary and alternative medicine: 1. A learning structure for clinical decision changes. J Altern Complement Med 2002; 8: 207-14.

[10] Sierpina V. Progress notes: a review of educational developments in CAM. Altern Ther Health Med 2002; 8: 104-6.

[11] van Tulder M, Furlan A, Bombardier C, Bouter L, Editorial Board of the Cochrane Collaboration Back Review Group. Updated guidelines for systematic reviews in the Cocrhane Collaboration Back Review Group. Spine 2003; 12: 1290-9.

[12] Gagnier JJ, van Tulder MW, Berman B, Bombardier C. Herbal medicine for low-back pain. Cochrane Database Syst Rev 2006; (2): CD004504.

[13] Yelland MJ, Del Mar C, Pirozzo S, Schoene ML, Vercoe P. Prolotherapy injections for chronic low-back pain. Cochrane Database Syst Rev 2007; (2): CD004059.

[14] Clarke JA, van Tulder MW, Blomberg SEI, et al. Traction for low back pain with or without sciatica. Cochrane Dalabase Syst Rev 2007; 18(2): CDOO390..

[15] Furlan AD, vanTulder MW, Cherkin DC, et al. Acupuncture and dry needling for low back pain. Cochrane Dalabase Syst Rev 2005; 25(1): CDOO1351.

[16] Liu JP, Zhang M, Wang WY, Grimsgaard S. Chinese herbal medicines for type 2 diabetes mellitus. Dalabase Syst Rev 2004; (3): CDOO3642.

[17] Setty AR, Sigal LH. Herbal medicines commonly used in the practice of rheumatology: mechanisms of action, efficacy, and side effects. Semin Arthritis Rheum 2005; 34: 773-84.

[18] Weiner DK, Ernst E. Complementary and alternative approaches to the treatment of persistent musculoskeletal pain. Clin J Pain 2004: 20(4); 244-55.

[19] Chrubasik S, Zimpfer C, Schütt U, Ziegler R. Effectiveness of Harpagophytum procumbens in treatment of acute low back pain. Phytomedicine 1996; 3: 1-10.

[20] Chrubasik S, Junck H, Breitschwerdt H, Conradt C, Zappe H. Effectiveness of Harpagophytum extract WS 1531 in the treatment of exacerbation of low back pain: a randomized, placebocontrolled, double-blind study. Eur J Anaesthesiol 1999; 16: 11829.

[21] Chrubasik S, Eisenberg E, Balan E, Weinberger T, Luzzati R, Conradt C. Treatment of low back pain exacerbations with willow bark extract: a randomized double-blind study. Am J Med 2000; 109: 9-14.

[22] Krivoy N, Pavlotzky E, Chrubasik S. Effects of salicis cortex extract on human platelet aggregation. Planta Med 2000; 67: 20912.
[23] Ginsberg F, Famaey JP. A double-blind study of topical massage with Rado-Salil ointment in mechanical low-back pain. J Int Med Res 1987; 15: 148-53.

[24] Keitel W, Frerick H, Kuhn U, Schmidt U, Kuhlmann M, Bredehorst A. Capsicum pain plaster in chronic non-specific low back pain. Arzneimittelforschung 2001; 51: 896-903.

[25] Chrubasik S, Model A, Black A, Pollak S. A randomized doubleblind pilot study comparing Doloteffin and Vioxx in the treatment of low back pain. Rheumatology (Oxford) 2003; 42: 141-8.

[26] Chrubasik S, Kunzel O, Model A, Conradt C, Black A. Treatment of low back pain with a herbal or synthetic anti-rheumatic: a randomized controlled study. Willow bark extract for low back pain. Rheumatology (Oxford) 2001; 40: 1388-93.

[27] Stam C, Bonnet MS, van Haselen RA. The efficacy and safety of a homeopathic gel in the treatment of acute low back pain: a multicentre, randomized, doubleblind comparative clinical trial. $\mathrm{Br}$ Homeopath J 2001; 90: 21-8.

[28] Yip YB, Tse SH. The effectiveness of relaxation acupoint stimulation and acupressure with aromatic lavender essential oil for non-specific low back pain in Hong Kong: a randomised controlled trial. Complement Ther Med 2004; 12: 28-37.

[29] Yelland MJ, Glasziou PP, Bogduk N, Schluter PJ, McKernon M. Prolotherapy injections, saline injections and exercises for chronic low back pain: a randomised trial. Spine 2004; 29(1): 9-16.

[30] Letizia MG, Martorana U, Cataldo P, Brancato G, Letizia G. Vitamin B12 in low back pain: a randomised, double-blind, placebo controlled trial. Eur Rev Med Pharmacol Sci 2000; 4(3): 53-58.

[31] Grant L, McBean DE, Fyfe L, Warnock AM. A review of the biological and potential therapeutic actions of Harpagophytum procumbens. Phytother Res 2007; 21: 199-209.

[32] Vlachojannis, JE, Cameron M, Chrubasik S. A systematic review on the effectiveness of willow bark for musculoskeletal pain. Phytother Res 2009; 23: 897-900.

[33] Mason L, Moore RA, Derry S, et al. Systematic review of topical capsaicin for the treatment of chronic pain. BMJ 2004; 328: 991.

[34] Hajhashemi V, Ghannadi A, Sharif B. Anti-inflammatory and analgesic properties of the leaf extracts and essential oil of Lavandula angustifolia Mill. J Ethnopharmacol 2003; 89: 67-71.

[35] Muller-Landgraf I. History of vitamins. Ther Umsch 1994; 51(7): 459-61.

[36] Groff JL, Gropper SS. Advanced nutrition and human metabolism. $3^{\text {rd }}$ ed. Australia: Wadsworth 2000.

[37] Gagnier JJ, Rochon PA, Boon H, Barnes J, Moher D, Bombardier $\mathrm{C}$, for the CONSORT Group. Improving the reporting of randomized controlled trials of herbal medicine interventions: explanation and elaboration. J Clin Epidemiol 2006; 59: 1134-49.

[38] Gagnier JJ, Rochon PA, Boon H, Barnes J, Moher D, Bombardier $\mathrm{C}$, for the CONSORT Group. Improving the reporting of randomized controlled trials of herbal medicine interventions: An application of the CONSORT statement. Ann Inter Med 2006; 144: 364-7.

[39] Gagnier JJ, Rochon PA, Boon H, Barnes J, Moher D, Bombardier $\mathrm{C}$, for the CONSORT Group. Improving the reporting of randomized controlled trials of herbal medicine interventions: An application of the CONSORT statement. Explore: J Sci Healing 2006; $2: 2$.

[40] Boutron I, Moher D, Altman DG, Schulz KF, Ravaud P. Extending the CONSORT statement to randomized trials of nonpharmacologic treatment: explanation and elaboration. Ann Intern Med 2008; 148(4): 295-309.

\section{(C) Joel J. Gagnier; Licensee Bentham Open.}

This is an open access article licensed under the terms of the Creative Commons Attribution Non-Commercial License (http://creativecommons.org/licenses/by-nc/3.0/) which permits unrestricted, non-commercial use, distribution and reproduction in any medium, provided the work is properly cited. 